\title{
Reserva de Vagas para Negros e Pardos: Concursos Públicos para Docente do Instituto Federal de Alagoas
}

\author{
Vacancies of Reserve for Blacks and Pardos: Public Procurement for \\ Teachers Institute of Federal Alagoas
}

\author{
Vacantes de Reserva para los Negros y Pardos: Contratación Pública \\ para Profesores de Instituto Federal Alagoas
}

\author{
Geórgia Valéria Andrade Loureiro Nunes ${ }^{1}$ \\ Dra. Verônica Teixeira Marques ${ }^{2}$
}

\begin{abstract}
Resumo
O presente trabalho visa analisar a implantação da Lei de Cotas (Lei 12.990/2014), que reserva 20\% das vagas em concursos públicos federais para negros e pardos, no âmbito do Instituto Federal de Alagoas. A análise partir do estudo de três editais desta instituição, publicados após a entrada em vigor da lei para o período de fevereiro de 2015 a junho de 2016, para contratação de docentes e técnicos administrativos em educação no que tange a autodeclaração de cor. A Lei de Costas para o serviço público federal estabelece que os candidatos para concorrer às vagas reservadas devam fazer a autodeclaração de cor no ato da inscrição. Verificam-se nos editais analisados que para a contratação de docentes exige-se a apresentação de fotografia para que haja a averiguação por comissão competente da cor declarada. Entretanto, o mesmo não ocorre nos editais destinados à contratação de técnicos administrativos em educação, para qual é solicitado somente a autodeclaração. Observa-se que o percentual das vagas reservadas é pequeno se comparado à quantidade de vagas gerais ofertadas. A análise dos editais, os quais já têm resultados publicados, permite verificar a pequena quantidade de candidatos aprovados para as vagas reservadas.
\end{abstract}

Palavras-Chave: Ações Afirmativas; Lei 12.990/2014; Autodeclaração.

\begin{abstract}
The present study aims to analyze the implementation of the Law of Cotas (Law 12.990 / 2014), which reserves $20 \%$ of vacancies in federal public tenders for blacks and pardos, within the Federal Institute of Alagoas. The analysis starts from the study of three edicts of this institution, published after the entry into force of the law for the period from February 2015 to June 2016, for the hiring of teachers and administrative technicians in education with regard to self-declaration of color. The Federal Public Service Costs Law establishes that applicants to apply for reserved positions must make their self-declaration of color upon registration. It is verified in the edits analyzed that for the hiring of teachers, the presentation of a photograph is required so that the competent committee can verify the declared color. However, the same does not occur in the notices for the hiring of administrative technicians in education, for which only the self-declaration is requested. It should be noted that the percentage of vacancies reserved is small compared to the number of vacancies offered. The analysis of the notices, which already have published results, allows to check the small number of candidates approved for the reserved places.
\end{abstract}

Keywords: Affirmative Action; Law 12.990 / 2014; Self-declaration.

\footnotetext{
${ }^{1}$ Bela. em Direito, mestranda em Sociedade, Tecnologias e Políticas Públicas; Centro Universitário Tiradentes UNIT; Alagoas, Maceió, Brasil; georgiavalerianunes@gmail.com.

2 Doutora em Ciências Sociais; Centro Universitário Tiradentes - UNIT; Alagoas, Maceió, Brasil; veronica_marques@set.edu.br.
} 


\section{Resumen}

Este estudio tiene como objetivo analizar la aplicación de la Ley de Cuotas (Ley Federal $N^{\circ} 12.990$ / 2014), que reserva el $20 \%$ de las plazas en los exámenes públicos federales para negros y pardos en el ámbito del Instituto Federal de Alagoas - IFAL. El análisis del estudio de cuatro edictos del IFAL, publicados tras la entrada en vigor de la ley para el período comprendido entre febrero de 2015 a junio de 2016, para contratar docentes y técnicos administrativos en educación, en relación con el auto declaración del color. La Ley de Cuotas para el servicio público federal establece que los candidatos para concurrir a las plazas reservadas deban hacer el auto declaración del color en el momento de la inscripción. Se comprueba en los edictos analizados que para la contratación de docentes se exige todavía la presentación de fotografía para que haya la averiguación por la comisión competente del color declarado. Sin embargo, lo mismo no ocurre en los edictos destinados a la contratación de técnicos administrativos en educación para lo cual se requiere sólo el auto declaración. Se observa que el porcentaje de las plazas reservadas es pequeño comparada con la cantidad de las plazas generales ofrecidas. El análisis de los edictos, los cuales ya tiene resultados publicados, le permite comprobar el pequeño número de candidatos para las plazas reservadas.

Palabras clave: Acciones afirmativas; Ley de Cuotas 12.990 /2014; Auto declaración del color.

\section{INTRODUÇÃO}

O Instituto Federal de Alagoas (IFAL) atendendo as diretrizes da Lei $n$. 12.990/2014 realiza a reserva de vagas ofertadas para negros e pardos em seus concursos públicos para docente e técnico administrativo em educação no percentual de $20 \%$. Para concorrer a estas vagas reservadas deve o candidato no ato da inscrição no certame se declarar negro ou pardo. Para fazer a autodeclaração o candidato preenche o modelo próprio disponibilizado pela Instituição e, especificamente, para concorrer à vaga de docente deve anexar à autodeclaração fotografia de frente para averiguação preliminar.

No edital do Instituto Federal de Alagoas para a contratação de docentes analisado para este trabalho, Edital n. 29/PROEN/DGP, de 29 de março de 2016, consta que a declaração e a foto do candidato que se inscreveu para concorrer na reserva de vagas para negros e pardos será objeto de averiguação por "comissão competente do IFAL" (Edital n. 29/PROEN/DGP, item 16.6), mas não há especificação de quais são os profissionais que fazem parte desta comissão averiguadora.

O candidato ao fazer a autodeclaração como negro ou pardo o faz porque se identifica desta maneira. Neste sentido Marco Aurélio de Mello, Ministro do Supremo Tribunal Federal, manifestou criticamente em relação à exigibilidade de fotografia em relação ao exame de seleção para ingresso nos cursos superiores da Universidade de Brasília (UnB): "se alguém se declara negro é porque negro é... Vamos parar de imaginar que todos são salafrários". E concluiu: "Fotografia não comprova nada" (Weber; Gallucci, 2004, p.184).

É possível pressupor que o IFAL ao exigir a fotografia do candidato autodeclarado irá realizar a averiguação como base apenas no fenótipo? Quais são os critérios de aparência física que serão considerados? Em torno destas indagações este artigo pretende 
discutir como as ações afirmativas raciais estão sendo implementadas no âmbito do Instituto Federal de Alagoas.

Desta forma, o artigo analisa o processo de implantação das políticas públicas afirmativas no Brasil no que tange a questão de autodeclaração racial a partir do estudo de caso dos Editais do IFAL, para o período de junho de 2015 a junho de 2016, para a contratação de docentes e técnicos administrativos em educação.

\section{POLÍTICAS AFIRMATIVAS NO BRASIL}

As ações afirmativas no Brasil buscam mitigar a desigualdade brasileira. De acordo com Barbosa Gomes e Silva (2012) estas ações atacam o sistema educacional que para este autor é tradicionalmente segregador, pois:

(...) sempre reservou aos negros e pobres em geral uma educação de inferior qualidade, dedicando o essencial dos recursos materiais, humanos e financeiros voltados à educação de todos os brasileiros, a um pequeno contingente da população que detém a hegemonia política, econômica e social no País (BARBOSA GOMES e SILVA, 2012, p.86).

As discussões para a criação e implantação das ações afirmativas no Brasil giram em torno, principalmente, de dois fatores, um envolvendo a noção de compensação, decorrente da compreensão do período da escravidão que subjugou a população negra, e o outro como forma de enfrentamento ao racismo (MACIEL, 2012). Barbosa Gomes e Silva (2012) afirmam que as ações afirmativas visam a instituir "medidas compensatórias" uma vez que não é possível acabar com as desigualdades. As ações afirmativas atuariam como instrumentos de proteção das condições básicas de vida dos grupos que experimentam exclusão social (BARBOSA GOMES e SILVA, 2012, p. 86). Neste sentido temos que:

Em regra geral, justifica-se a adoção das medidas de ação afirmativa com o argumento de que esse tipo de política social seria apta a atingir uma série de objetivos que restariam normalmente inalcançados caso a estratégia de combate à discriminação se limitasse à adoção, no campo normativo, de regras meramente proibitivas de discriminação (GOMES BARBOSA, 2003, p.29).

Não podemos partir do pressuposto que o público-alvo das ações afirmativas é sempre grupos sociais minoritários, mas sim grupos que são discriminados negativamente. As ações afirmativas atuam como mecanismo de superar as desvantagens econômicas, social e política. A lei que estabeleceu a reserva de vagas em concursos públicos no âmbito federal para negros e pardos bem demonstra isto, pois este grupo social não é minoria na população, 
mas uma maioria que historicamente é colocada à margem dos processos educacionais e na ocupação de vagas no emprego público.

De acordo com dados Pesquisa Nacional por Amostragem de Domicílio (PNAD) de 2012, negros e pardos somam 53,1\% da população brasileira. Desta forma, não podemos atribuir a este grupo social a alcunha de minoria quando representam já a maioria da população brasileira (IBGE, 2012).

Entretanto apesar deste grupo social, negros e pardos, representar mais da metade da população o mesmo não se reflete quando analisamos os dados de servidores públicos federais. De acordo com a Nota Técnica do Ipea de 2013 negros e pardos ocupam 47,4\% dos cargos públicos federais (IPEA, 2013)

Oracy Nogueira (NOGUEIRA, 2007) em seus trabalhos distinguiu o preconceito "de marca" do preconceito "de origem". O primeiro vimitiza a aparência e se baseia nos traços físicos do indivíduo, enquanto o segundo depende da percepção de que o indivíduo descende de certo grupo étnico. Nogueira associou o preconceito "de marca" com o Brasil e o preconceito "de origem" com os Estados Unidos. No Brasil teríamos o preconceito ligado diretamente ao fenótipo do indivíduo.

Trazendo as definições de Oracy Nogueira para as ações afirmativas implantadas para os concursos docentes no âmbito do Instituto Federal de Alagoas que estabelecem a reserva de vagas para negros e pardos, serão os candidatos que concorrerem a estas vagas reservadas considerados negros ou pardos de acordo com a "origem" ou com "a marca"? Pode uma foto dizer quem é negro ou pardo? Pode uma "comissão competente" definir quem é ou não negro ou pardo e/ou confirmar a autodeclaração?

\section{A LEI 12.990/2014}

A mobilidade social e certos padrões de desigualdade no país ainda estão fortemente ligados à cor da pele ou ao "preconceito de marca" conforme definido por Oracy Nogueira (NOGUERIA, 2007), de forma a "restringir as possibilidades de ascensão social de não brancos em atividades não manuais e/ou que envolvessem contato com o público" (DELGADO, 2016, p.187).

De acordo com Delgado (DELGADO, 2016) o embate em torno da Lei $\mathrm{n}^{\circ}$ 12.711/2012 que estabeleceu a reserva de vagas para negros e pardos em universidade públicas federais tem entre os seus embates as dificuldades de apuração de quem é ou não negro e/ou pardo e as opiniões conservadoras de que o critério de seleção deve pautar-se apenas na meritocracia. Podem-se transportar estas mesmas considerações apontadas também 
para a Lei 12.990/2014 que reservou vagas para os negros e pardos nos concursos públicos federais. Por conseguinte, pode-se dizer que ambas as leis tem como escopo mitigar as desigualdades sociais e o enfrentamento ao racismo.

Em seu trabalho Delgado (DELGADO, 2016) aponta que as ações afirmativas para acesso ao Ensino Superior são exitosas e permitem refletir sobre a possibilidade de estendê-las a outras esferas:

(...) de modo a reduzir os gargalos existentes para a mobilidade social dos negros, como por exemplo, no acesso ao serviço público e na definição de critérios para as compras governamentais, de modo a favorecer empresas que adotem políticas de diversidade na composição de seus quadros de funcionários e de executivos (DELGADO, 2016, p.191).

A possibilidade de extensão das ações afirmativas para o acesso ao serviço público federal está concretizada na Lei 12.990, de 9 de junho de 2014. A proposta desta lei pautou-se no estudo do Instituto de Pesquisa Econômica Aplicada (Ipea) de 2014, que mostrou que, apesar de os negros ocuparem 47,4\% dos empregos no setor público federal a presença deste grupo é bastante reduzida nas carreiras mais valorizadas. O Ipea ainda apontou no seu estudo que é maior a aprovação de negros para cargos ao quais se exige baixa escolaridade e bem menor para os que exigem curso superior e envolvem maior remuneração. Por fim, neste trabalho o Ipea concluiu que apesar de medidas compensatórias já implantadas as desigualdades entre negros e pardos e brancos ainda persistem. (IPEA, 2014).

A Lei $12.990 / 2014$ estabelece a reserva de $20 \%$ das vagas para negros e pardos em concursos realizados para a administração pública federal, autarquias, fundações públicas, empresas públicas e sociedades de economia mista controladas pela União, mas não estende a sua abrangência ao Poder Legislativo e Judiciário.

A reserva de vagas para acesso a cargos públicos federais tem entre seus objetivos o enfrentamento ao racismo e mitigar as desigualdades sociais vez que negros e pardos são segregados nas carreiras que ocupam. Desta forma, passaremos a analisar como no Instituto Federal de Alagoas o acesso aos cargos de docente para os candidatos autodeclarados negros ou pardos é normatizado nos editais e se há diferenciação para os editais que regem a contratação de técnicos administrativos em educação.

\section{COMISSÃO AVERIGUAdORA PARA DEFINIR O QUE É NEGRO OU PARDO?}



e-ISSN 2016/Atual: 2525-7870 | e-ISSN 2015/2016: 2447-018X

O Instituto Federal de Alagoas em seus Editais para a contratação de docentes e técnicos administrativos em educação e em decorrência da obrigatoriedade da Lei 12.990/2014 reserva 20\% de suas vagas para candidatos negros e pardos. Consta nos editais que para concorrer a estas vagas reservadas o candidato deve preencher a declaração no modelo próprio disponibilizado pela Instituição. Entretanto, para concorrer à vaga de docente o candidato além de preencher a autodeclaração deve anexar foto de frente que será objeto de “averiguação por comissão competente do IFAL" (IFAL, Edital n. 29/PROEN/DGP, item 16.6). Não há especificação de como se dará o processo de averiguação, se esta será com base no fenótipo expresso na fotografia, e quais os profissionais que fazem parte da "comissão competente do IFAL".

Ao deparar com este texto no edital é possível remeter ao caso emblemático ocorrido na Universidade de Brasília em 2004 em que esta universidade reservou percentual de suas vagas em seus cursos superiores a negros e pardos, mas estabeleceu uma comissão para homologar a condição racial dos candidatos. Para isto, criou uma comissão a qual deveria avaliar os candidatos como base nos fenótipos apresentado nas fotografias dos candidatos (MAIO e SANTOS, 2005).

De acordo com Maio e Santos (MAIO e SANTOS, 2005) a comissão ao analisar as características físicas, visando identificar traços da raça negra criou constrangimentos diversos e dilemas identitários relativos às questões se os critérios seriam os mesmos de aparência física, negra, ou de afro-descendência.

Voltemos ao caso do Instituto Federal de Alagoas que exige foto para averiguação da cor por "comissão competente". Ao analisar o texto da Lei 12.990/2014 deparamos com a seguinte redação: "Poderão concorrer às vagas reservadas a candidatos negros aqueles que se autodeclararem negros ou pardos no ato da inscrição no concurso público, conforme o quesito cor ou raça utilizado pela Fundação Instituto Brasileiro de Geografia e Estatística - IBGE.” (Art. 2 $2^{\circ}$, Lei 12.990/2014). Pela leitura deste artigo fica evidente que não é possível a exigibilidade de comprovação de cor uma vez que para concorrer às vagas reservadas a negros e pardos basta a autodeclaração feita pelo candidato.

Ao analisar editais para contratação de docentes e técnicos administrativos em educação de outras Instituições de Ensino Federal como, por exemplo, os editais da Universidade Federal de Alagoas, verifica-se que não há a exigibilidade de comprovação da condição de negro ou pardo. Exige-se somente a autodeclaração de cor do candidato, feita no momento em que este realiza a sua inscrição no certame. 
Ao confrontar os editais para preenchimento de vagas do próprio Instituto Federal de Alagoas para a contratação de técnicos administrativos em educação, Edital no 59/2016 e Edital $n^{\circ}$ 60/2016, ambos de 13 de maio de 2016, verifica-se que estes exigem para os candidatos que concorrerão às vagas reservadas para negros e pardos apenas a autodeclaração, dispensam a apresentação de fotografia e em nenhuma parte do texto estabelecem a realização de qualquer forma de averiguação da condição racial do candidato diferentemente do que ocorre para as vagas de docente.

Assim, como pode ocorrer que editais da mesma instituição possuam posicionamentos diferenciado quanto ao acesso às vagas reservadas aos negros e partos? Este posicionamento estaria relacionado ao cargo visto que os editais que aceitam apenas a autodeclaração são para provimento de cargos técnicos administrativos em educação e o edital que exige a averiguação da condição de negro ou pardo é para a função de docente?

Como base nestas indagações cabe a reflexão sobre os dados apontados pelo Ipea de que negros e pardos não estão distribuídos de forma equivalente nas esferas do poder público, sendo bem reduzida nas carreiras mais valorizada, especialmente as de nível superior e que oferecem melhor remuneração (IPEA, 2014).

Adotando como referência este paradigma apresentado pelo Ipea de que negros e pardos dentro da esfera do serviço público federal ocupam ainda cargos marginalizados e com menores remunerações é possível correlacioná-la as normas estabelecidas pelo Instituto Federal de Alagoas para acesso aos seus cargos nos seus editais de seleção. O Instituto Federal de Alagoas ao estabelecer que os candidatos a vagas para docentes autodeclarados negros e pardos devam ter esta condição averiguada por "comissão competente" acaba criando obstáculos para que este grupo social tenha acesso a esta função que dentre os cargos da Instituição é considerada mais prestigiada, com maiores vencimentos e que exigem maior escolaridade do que as dos técnicos administrativos em educação.

\section{REFERÊNCIAS}

BRASIL. Lei 12.990/2014, de 9 de junho de 2014. Diário Oficial [da] República

Federativa do Brasil, Poder Executivo, Brasília-DF, 10 de jun. de 2014. Disponível em < http://www.planalto.gov.br/ccivil_03/_Ato2011-2014/2014/Lei/L12990.htm> Acesso em 13 de jun. de 2016.

DELGADO, Ignacio José Godinho. Ações afirmativas e o horizonte normativo da democracia racial (Affirmative actions and the normative horizon of racial democracy). Cadernos de 
História, v. 17, n. 26, p. 182-197, 2016. Disponível em

<http://periodicos.pucminas.br/index.php/cadernoshistoria/article/viewFile/10606/9563> Acesso em 8 de jul. de 2016.

GOMES, Joaquim Barbosa. A recepção do instituto da ação afirmativa pelo direito constitucional brasileiro. In: SANTOS, Sales Augusto dos (Org.). Ações afirmativas e combate ao racismo nas Américas. Brasília: Ministério da Educação, Secretaria de Educação Continuada, Alfabetização e Diversidade, 2005. p. 45-79. Disponível em < http://adami.adv.br/artigos/19.pdf> Acesso em 23 de jun. de 2016.

GOMES, Joaquim Barbosa. O debate constitucional sobre as ações afirmativas. Ações afirmativas: políticas públicas contra as desigualdades raciais. Rio de Janeiro: DP\&A, p. 15-58, 2003. Disponível em <http://www.scielo.br/scielo.php?script=sci_arttext\&pid=S010133002010000200005> Acesso em 13 de jun. de 2016.

\section{INSTITUTO BRASILEIRO DE GEOGRAFIA E ESTATÍSTICA. Pesquisa nacional por} amostra de domicílios. Rio de Janeiro: IBGE, 2012.

INSTITUTO DE PESQUISA ECONÔMICA APLICADA - IPEA-DISOC. Reserva de vagas para negros em concursos públicos: uma análise a partir do Projeto de Lei 6.738/2013. Nota Técnica Brasília, n. 17, fev. 2014. Disponível em <http://repositorio.ipea.gov.br/bitstream/11058/5781/1/NT_n17_Reserva-vagas-negrosconcursos-publicos_Disoc_2014-fev.pdf> Acesso em 8 de jul. de 2016.

INSTITUTO FEDERAL DE ALAGOAS. Edital n. 59/2016, de 12 de maio de 2016. Alagoas, 2016. Diário Oficial [da] República Federativa do Brasil, Poder Executivo, Brasília-DF, 13 de jun. de 2016. Disponível em < http://www.copeve.ufal.br/sistema/anexos/Instituto\%20Federal\%20de\%20Alagoas\%20\%20Tecnico-Administrativo\%20-\%20Edital\%20n.060-2016\%20\%20Fundamental\%20e\%20Superior/Edital\%2060.2016\%20\%20Retificado\%20em\%2010.06.2016.pdf> Acesso em 17 de jul. de 2016.

Edital n. 60/2016, de 12 de maio de 2016. Alagoas, 2016. Diário Oficial [da]

República Federativa do Brasil, Poder Executivo, Brasília-DF, 30 de mar. de 2016.

Disponível em < http://www.copeve.ufal.br/sistema/anexos/Instituto\%20Federal\%20de\%20Alagoas\%20- 

e-ISSN 2016/Atual: 2525-7870 | e-ISSN 2015/2016: 2447-018X

\%20Tecnico-Administrativo\%20-\%20Edital\%20n.059-2016\%20-

\%20Medio/Edital\%2059.2016\%20-\%20Retificado\%20em\%2010.06.2016.pdf> Acesso em 17 de jul. de 2016.

Edital n. 29/PROEN/DGP, de 29 de mar. de 2016 . Diário Oficial [da]

República Federativa do Brasil, Poder Executivo, Brasília-DF, 30 de mar. de 2016.

Disponível em

<.http://concurso.ifal.edu.br/files/Edital\%20Professor\%20Efetivo\%20\%202016\%20versao\%2 Oretificada.pdf> Acesso em 17 de jul. de 2016.

MACIEL, Regimeire Oliveira. Ações afirmativas na Universidade Federal do Maranhão.

Revista Brasileira de Estudos Pedagógicos, v. 93, n. 233, 2012. Disponível em

<http://rbep.inep.gov.br/index.php/rbep/article/viewFile/466/452> Acesso em 13 de jun. de 2016.

MAIO, Marcos Chor; SANTOS, Ricardo Ventura. Política de cotas raciais, os "olhos da sociedade" e os usos da antropologia: o caso do vestibular da Universidade de Brasília (UnB). Horizontes antropológicos, v. 11, n. 23, p. 181-214, 2005. Disponível em < http://www.scielo.br/scielo.php?script=sci_arttext\&pid=S0104-71832005000100011> Acesso em 13 de jun. de 2016.

NOGUEIRA, Oracy. Preconceito racial de marca e preconceito racial de origem: sugestão de um quadro de referência para a interpretação do material sobre relações raciais no Brasil. Tempo social. v. 19, n. 1, p. 287-308, 2007.

Pesquisa nacional por amostra de domicílios: síntese de indicadores 2013 / IBGE, Coordenação de Trabalho e Rendimento. - 2. ed. - Rio de Janeiro : IBGE, 2015. Disponível em < http://biblioteca.ibge.gov.br/visualizacao/livros/liv94414.pdf> Acesso em 25 de jun. de 2016.

UNIVERSIDADE FEDERAL DE ALAGOAS. Edital n. 16/2016, de 12 de abr. de 2016. Diário Oficial [da] República Federativa do Brasil, Poder Executivo, Brasília-DF, 13 de abr. de 2016. Disponível em < http://www.copeve.ufal.br/sistema/anexos/Docente\%20UFAL\%20Efetivo\%20\%20Edital\%20n.016-2016\%20- 

e-ISSN 2016/Atual: 2525-7870 | e-ISSN 2015/2016: 2447-018X

\%20Arapiraca/Edital\%20De\%20Abertura\%20N\%20162016\%20\%20(retificado\%20Em\%202 9042016).pdf> Acesso em 17 de jul. de 2016.

WEBER, D.; GALLUCCI, M. Política de Cotas Raciais, os "Olhos da Sociedade" e os Usos da Antropologia: O Caso do Vestibular da Universidade De Brasília (Unb).In: Raça como questão: história, ciência e identidades no Brasil. Rio de Janeiro: Fiocruz (2010).

Disponível em: <http://www.scielo.br/pdf/ha/v11n23/a11v1123.pdf>. Acesso em: 23 de junho de 2016. 